\title{
Can Silent Reading in the Summer Reduce Socioeconomic Differences in Reading Achievement?
}

\section{Citation}

White, Thomas G. and James S. Kim. 2010. Can silent reading in the summer reduce socioeconomic differences in reading achievement? In Revisiting silent reading: New directions for teachers and researchers, eds. E.H. Hiebert and D.R. Reutzel, 67-94. Newark, DE: International Reading Association.

\section{Permanent link}

http://nrs.harvard.edu/urn-3:HUL.InstRepos:28981324

\section{Terms of Use}

This article was downloaded from Harvard University's DASH repository, and is made available under the terms and conditions applicable to Open Access Policy Articles, as set forth at http:// nrs.harvard.edu/urn-3:HUL.InstRepos:dash.current.terms-of-use\#OAP

\section{Share Your Story}

The Harvard community has made this article openly available.

Please share how this access benefits you. Submit a story.

\section{Accessibility}


CITATION: White, T.G., \& Kim, J.S. (2010). "Can Silent Reading in the Summer Reduce Socioeconomic Differences in Reading Achievement?” In Hiebert, E.H., \& Reutzel, D.R. (Eds.), Revisiting Silent Reading: New Directions for Teachers and Researchers (pp. 67-94). Newark, DE: International Reading Association.

\title{
Can Silent Reading in the Summer Reduce Socioeconomic Differences in Reading Achievement?
}

\author{
Thomas G. White \\ University of Virginia \\ and \\ James S. Kim \\ Harvard University
}

This chapter addresses an important issue for education policymakers and practitioners in the United States. The question we ask is whether socioeconomic differences in reading achievement can be reduced by programs that encourage silent reading in the summer months. ${ }^{1}$ In the years following school entry, children of low socioeconomic status (SES) lose ground in reading relative to their high-SES counterparts. This widening achievement gap may be largely the result of different rates of learning during the summer months (e.g., Alexander, Entwisle, \& Olson, 2001; Cooper, Nye, Charlton, Lindsay, \& Greathouse, 1996; Heyns, 1978). Even small differences in summer learning can accumulate across years resulting in a substantially greater achievement gap at the end of elementary school than was present at the beginning (Alexander, Entwisle, \& Olson, 2004; see also Borman \& Dowling, 2006; Lai, McNaughton, AmituanaiToloa, Turner, \& Hsiao, 2009).

As Heyns (1978) suggested more than 30 years ago, increasing low-income children's access to books and encouraging them to read in the summer might go a long way towards reducing seasonal differences in learning and achievement gaps. Although this powerful idea may be one whose time has finally come, it needs to be more fully developed and tested in a methodologically rigorous way. We need to know, for example, whether mere access to books is sufficient, and specifically how to encourage children to read during their summer vacation. And we need experimental studies to establish the effectiveness of any interventions that are developed before they are widely implemented with children.

\footnotetext{
${ }^{1}$ We have chosen to focus on socioeconomic differences instead of differences in race/ethnicity or other factors (e.g., home language) that may be related to growth in reading achievement for several reasons. First, our review of the literature suggested that summer learning seems to be influenced primarily by SES. With SES controlled, the effects of race/ethnicity on summer learning are inconsistent at best, although it is well established that race/ethnicity is associated with different rates of learning during the school year net of SES. Second, as a practical matter, we have found that summer reading programs targeting low-SES students are easier to justify than programs that target particular racial groups. Third, programs for low-SES students are likely to reduce racial/ethnic and language achievement gaps because ethnic and language minority students are disproportionately poor.
} 
We have been pursuing the question of how to enhance silent summer reading while addressing socioeconomic differences in reading achievement for the past seven or eight years. In the process, we developed what we call a "scaffolded" summer reading program and conducted two randomized experiments to test its effectiveness (Kim, 2006; Kim \& White, 2008). In the next three sections, to provide a backdrop, we review research on socioeconomic differences in reading achievement and summer learning and some possible explanations of those differences. Then, in the heart of the chapter, we explain our thinking as we approached the task of developing the summer reading program, present the logic model underlying it, describe the experiments, give the details of the program, present findings, and describe related research and similar programs that are being implemented by others. We conclude with a set of recommendations for researchers and policymakers.

\section{Socioeconomic Differences in Reading Achievement}

Data from the nationally representative Early Childhood Longitudinal Study, Kindergarten Class of 1998-1999 (ECLS-K) show that poor children begin kindergarten with average reading scores that fall .58 standard deviation (SD) units below those of non-poor children, and that the gap between poor and non-poor children increases to .65 SD by the end of first grade and to .79 SD by the end of third grade (LoGerfo, Nichols, \& Reardon, 2006, Tables 3.9 and C1). " "Poor" children are defined here as children who are eligible for the federal free and reduced lunch program. Aikens and Barbarin (2008) analyzed ECLS-K reading growth trajectories from kindergarten through third grade by SES quintile, five categories based on father's (or male guardian's) education and occupation, mother's (or female guardian's) education and occupation, and household income. The difference between children in the highest and lowest SES quintiles increased from 11.3 points at kindergarten entry or about 6 months of learning to 27.2 points at the end of third grade or about 16 months of learning. ${ }^{3}$ These studies demonstrate, in practical terms, that the SES gap in reading achievement is already large when children begin school, and it grows distressingly larger by the end of third grade.

Whether the SES gap in reading achievement continues to widen after third grade is not yet clear. To answer this question well, it is necessary to have a large and representative sample of children followed to fourth grade and later, to control for previous scores at each point in time where the gap is assessed, and to correct for error of measurement (see, e.g., Phillips, Crouse, \& Ralph, 1998). Cross sectional studies like the National Assessment of Educational Progress (NAEP) conflate changes in the achievement gap with changes that are occurring in society and/or schools over time. Also, because reading test scores collected in different years are imperfectly correlated (i.e., there is error of measurement), initially low-scoring low-SES children may appear to improve in relation to initially high-scoring high-SES children, due to a regression-to-the-mean artifact. The ECLS-K study meets the first criterion and has now been extended to the fifth and eighth grades. However, investigators are just beginning to examine the

\footnotetext{
${ }^{2}$ LoGerfo et al. (2006) point out that the standard deviation of the ELCS-K reading test increases with each successive wave of data collection, so in comparing gaps it is necessary to divide the observed difference between groups at each point in time by the corresponding standard deviation (i.e., to use an effect size metric).

${ }^{3}$ Following Aikens \& Barbarin (2008), we calculated the initial SES gap in months of learning by dividing the difference between the highest and lowest quintiles (11.3 points) by the learning rate for the kindergarten year, 1.86 points per month. For the gap in months at the end third grade, we divided the difference between the highest and quintiles, 27.2, by the learning rate from the end of first grade to the end of third grade, 1.66 points per month.
} 
ECLS-K fifth and eighth grade data, and as of this writing, no studies have focused on the issue of whether SES (or racial) differences increase beyond third grade.

We do know that SES is associated with large differences in reading achievement in the upper elementary grades and beyond. For instance, results from the 2007 National Assessment of Educational Progress (NAEP) Reading test show a gap of .83 SD at fourth grade and a gap of $.73 \mathrm{SD}$ at eighth grade between children who are eligible for free or reduced-price lunch and children who are not (Lee, Grigg, \& Donahue, 2007). ${ }^{4}$ The smaller gap at eighth grade may reflect under-reporting of free lunch eligibility at higher grade levels or a cohort effect. It seems implausible that socioeconomic differences in reading achievement decrease after third grade because vocabulary, knowledge, and comprehension demands increase (e.g., Becker, 1977; Biemiller, 1999; Chall, 1983) and low-income children have smaller vocabularies and more limited knowledge (e.g., Chall, Jacobs, \& Baldwin, 1990; Hart \& Risley, 1995; White, Graves, \& Slater, 1990). In addition, there is considerable evidence (reviewed below) that low-SES children make less progress in reading than high-SES children in the summers following third through eighth grade, so an increasing achievement gap would be expected if there are no compensatory learning differences during the school year.

\section{The Role of Summer Learning in the Development of SES Differences in Reading}

In this section, we address three questions: (1) Do summer learning differences contribute to an SES achievement gap that is growing larger, almost certainly during the early years of schooling and probably in the later elementary and early middle school years as well? (2) If so, do school-year or summer learning differences make a larger contribution to the growing gap? (3) Are there racial/ethnic differences in summer learning that are independent of SES?

Do summer learning differences contribute to the SES achievement gap? Cooper et al's (1996) meta-analysis examined the effects of summer vacation on the reading achievement of first through eighth grade students (i.e., the summers following first through eighth grade). Combining grades, there was a significant effect of SES on summer learning. Middle-income students made a non-significant gain (+ .06 SD in grade-level equivalents) while low-income students showed a significant loss (- .21 SD), based on 37 independent samples. The difference between grade-level equivalent scores in the fall and spring was +.16 for middle-income students and - .19 for low-income students, which is a difference of about 3 months of school-year learning.

The classic study of summer learning by Barbara Heyns (1978) was among the studies reviewed by Cooper et al. (1996). Heyns studied a stratified sample of Atlanta public schools that included several thousand sixth and seventh grade students who were tested, during the early 1970s, in the fall and spring of the school year and again in the following fall. The dependent variable in her analyses was the Word Knowledge subtest of the Metropolitan Achievement

\footnotetext{
${ }^{4}$ We calculated the gap by dividing the difference in scaled score points, 27 and 24 points for fourth and eighth grade respectively, by the standard deviations for each grade, 32.6 and 32.8, which were calculated by weighting the standard deviation for each group by its sample size as a proportion of the total sample.
} 
Tests, a measure of reading vocabulary. ${ }^{5}$ Heyns (1978) found that (1) students of every income level learned at a slower rate during the summer than during the school year, (2) there were marked socioeconomic differences in learning, and (3) the socioeconomic differences were especially prominent during the summer months. High-income sixth and seventh grade students with family incomes of at least $\$ 15,000$ improved their reading skills in the summer, while lowincome students with family incomes of less than $\$ 9,000$ either showed summer loss (sixth graders) or made no gain (seventh graders).

Another important study included in Cooper et al.'s (1996) meta-analysis was the Beginning School Study (BSS), a longitudinal study that followed 665 children in Baltimore schools from first through fifth grade (e.g., Entwisle, Alexander, \& Olson, 1997; Alexander et al., 2001; Alexander et al., 2004). In the BSS, a standardized test of reading comprehension, the California Achievement Test, was given in the fall and spring of each year. Family SES was measured as a composite including mother's and father's education and occupation and receipt of reduced-price meals, and the composite was used to form three SES groups-high, medium, and low. The results of growth curve analyses by Alexander et al. (2001) showed that, during each school year, there were similar gains in reading for low-SES and high-SES children . ${ }^{6}$ There was, however, significant SES differentiation in the summer. Low-SES children showed small losses or very modest gains in the summer, whereas high-SES children gained. Figure 1 plots fall and spring CAT-V Reading Comprehension scores for the two SES groups. Between the spring and fall data points, the growth trajectories are clearly different, and the cumulative impact of summer loss or differentiation is apparent from the widening gap.

\section{Figure 1-Reading Achievement Gains by Season and SES}

(Seek permission to reproduce Fig 2.3 from Alexander et al., 2004)

Kim (2004) followed a sample of about 1700 ethnically diverse students who took reading tests in the spring of fifth grade and the fall of sixth grade in 18 schools in a suburban midAtlantic school district. He found that, holding constant spring scores and other background characteristics, poor students receiving free- or reduced-price meals had significantly lower fall reading scores than non-poor students.

Other studies of summer learning conducted since the Cooper et al. (1996) meta-analysis have focused on the early elementary years. Because our summer reading program targeted poor children in third, fourth, and, fifth grades, this work is less germane, but it adds support to the conclusion that low-SES children learn less than high-SES children when school is not in session. Phillips and Chinn (2004) analyzed data for a subsample of 1141 children who were tested in the fall of second grade as well as spring of first grade as part of the Congressionally mandated Prospects study conducted in the early 1990s. For Reading Vocabulary, children from poor families with incomes of less than $\$ 15,000$ per year showed a small loss during the summer

\footnotetext{
${ }^{5}$ The Word Knowledge subtest was chosen because it was the most reliable subtest and most highly correlated with the main factor extracted from a factor analysis of all the subtests including Reading (comprehension), Language, Language Study Skills, and five subtests of mathematics, social studies, and science achievement.

${ }^{6}$ This result should be interpreted cautiously because there were no genuinely high SES children in the BSS; mother's education averaged only 14.6 years in the high-SES group (Alexander et al., 2001).
} 
following first grade, and children from non-poor families showed a small gain. For Reading Comprehension, poor children gained ground while non-poor children lost ground—an anomalous finding that was not explained.

Because the research of Heyns (1978) and others had suggested that there were seasonal differences in learning, the ECLS-K study tested participating children in the fall of their first grade year in a random sample of 30 percent of the original ECLS-K schools. This subsample of about 4,000 children has allowed at least six sets of investigators to examine learning rates in the summer following kindergarten (Benson \& Borman, 2007; Burkam, Ready, Lee, \& LoGerfo, 2004; Cheadle, 2008; Downey, von Hippel, \& Broh, 2004; LoGerfo et al., 2006; McCoach, O’Connell, Reis, \& Levitt, 2006). These studies found no summer gains in reading for all children and significant differences by SES group. High-SES children made reading gains while low-SES children lost ground in the summer. For example in Burkam et al.'s (2004) study, children in the highest SES quintile gained .07 SD, whereas children in the lowest SES quintile lost .09 SD when compared to the middle-SES group. ${ }^{7}$

In summary, Cooper et al's (1996) meta-analysis, Heyns' study (1978), Alexander et al.'s (2001) study, Kim's (2004) study, and analyses of data from the ECLS-K (e.g., Burkam et al., 2004) and Prospects study (Phillips \& Chinn, 2004) are consistent in showing that there is significant SES differentiation in the summer months following kindergarten through eighth grade, such that low-SES children fall behind their high-SES peers in reading.

School-year versus summer learning differences. In their analyses of ECLS-K data, Benson \& Borman (2007), Cheadle (2008), Downey et al. (2004), LoGerfo et al. (2006, Table 5.3), and McCoach et al. (2006) all found that high-SES children learned more than low-SES children during the school year as well as the summer. They also found that there were larger socioeconomic differences in reading growth rates during the summer than during the school year. For example, in Benson and Borman's (2007) study, the gap between the highest and lowest SES quintiles increased by about 0.5 points per month in the summer between kindergarten and first grade and about 0.2 points per month in both kindergarten and first grade. Benson and Borman (2007) point out that the school year is longer than the summer (9.4 months vs. 2.6 months in their calculation), so the summer made a smaller contribution to SES differences overall, about 1.4 points compared to 1.9 points, or about $42 \%$ of the annual increase in the achievement gap.

In contrast to Benson and Borman (2007), Alexander et al. (2001) found that the summer months make the largest contribution to SES differences. In their growth curve analyses, with a summer adjustment term included in the model, the effect of SES was not significant and trivially small in a negative (not positive) direction. Thus they stated that "the BSS conclusion is that practically the entire gap increase across socioeconomic lines traces to summer learning differentials" (Alexander et al., 2001, p. 174; italics in original; see also Entwisle et al., 1997, p. 38).

\footnotetext{
${ }^{7}$ The other studies analyzed summer learning differentials using a continuous measure of SES, the standardized SES composite (Cheadle, 2008; Downey et al., 2004; McCoach et al., 2006) or a dichotomous measure, eligibility for free- or reduced-price lunch (LoGerfo et al., 2006). We prefer Burkam et al.’s approach because these measures may be insensitive, particularly to non-linear effects of SES.
} 
On the issue of school-year versus summer learning differences, Heyns (1978) took a position that falls somewhere between Alexander et al. (2001) and Benson and Borman (2007). Unlike Alexander et al. (2001), she did find SES differentiation in the school year as well as the summer. The degree of differentiation varied with both the grade level and students' race. The difference in gains, in grade-level equivalents, between students in the highest versus lowest income category ranged from .04 to .35 in the school year and from .22 to .70 in the summer. Summer learning differences accounted for 39 to 95 percent of the annual increase in the SES gap. ${ }^{8}$ When Heyns looked at the increasing gap between national norms and the total Atlanta sample comprised of students who were in general economically disadvantaged, she concluded that the summer differential "is responsible for perhaps $80 \%$ of the gap” (1978, p. 68).

In sum, the answer to the question of whether school-year or summer learning differences make the largest contribution to the SES gap in reading is that it depends on the sample. Based on the available evidence, summer learning differences account for as little as $40 \%$ to as much as $100 \%$ of the annual increase in the gap. In urban disadvantaged settings like those studied by Alexander et al. (2001) and Heyns (1978), it is apt to be closer to $100 \%$ than to $40 \%$. What is clear in any event is that the rate of differentiation is greater during the summer months. For this reason, it makes sense to develop reading interventions for poor children that are designed to be implemented in the summer.

Racial/ethnic differences in summer learning net of SES. Heyns (1978) conducted regression and path analyses showing that race/ethnicity (Black versus White) affects summer learning even when family income, parental education, and household size are controlled. She found that, for middle- and lower-income groups, White students either gained or showed no reading growth in the summer, while Black students either made smaller gains than White students or lost ground. Subsequent research, however, has not provided consistent support for Heyns’ conclusion that race/ethnicity affects summer learning net of SES.

Phillips and Chin (2004) reported a marginally significant $(p<.10)$ negative effect for Black children on summer reading comprehension gains with family income controlled, but only when spring scores, teacher ratings, children's activities, and family literacy practices were included in the statistical model. Kim (2004) also found a significant negative effect of Black ethnicity on summer reading gains with SES already accounted for. However, Cooper et al. (1996) found that race did not have a consistent moderating influence on the effect of summer vacation. And Alexander et al (2001) found that with SES already in their statistical model, there were no effects for race on reading during any of the four summers studied.

Perhaps the best evidence on the question of race/ethnicity effects on summer learning comes from the ECLS-K studies reviewed earlier, including Benson and Borman (2007), Cheadle (2008), Downey et al. (2004), and McCoach et al. (2006). In contrast to Phillips and Chin (2004) and Kim (2004), these studies used a non-dichotomous measure of SES, SES quintile. They found that, once SES was accounted for, the summer learning rates of Black or Hispanic children were not lower than those of White children.

\footnotetext{
${ }^{8}$ We calculated these percentages from the data in Heyns (1978, Tables 3.1. and 3.2, pp. 45-46).
} 


\section{Why Do Low-SES Children Make Less Progress in Reading in the Summer Months?}

We suggest, first, that spring-to-fall growth in reading achievement is affected by the amount of summer reading that children do. Second, the amount of reading that children do in the summer is influenced by (a) access to books and other reading materials in the home environment and outside of the home, and (b) family support for reading and literacy-related activities. Finally, access and family support are influenced by socioeconomic status. In other words, the effect of SES on summer reading growth is mediated, at least in part, by access, support, and reading activity. So low-SES children make less progress in reading in the summer months than high-SES children because, among other factors, they have less access to books and less family support for reading and consequently read less. There is good evidence in the literature for the linkages between SES, access, and support, between access and amount of reading, and between amount of summer reading and fall reading achievement.

SES, book access, and family support. According to the "faucet theory" proposed by Entwisle et al. (1997), all children gain when they are in school because the resources needed for learning are available to them. But when school is not in session, the resource faucet is turned off, so inequalities in resources exert their effects, causing children from poor families to stop gaining or lose ground while non-poor children improve or at least maintain their skills. The faucet theory points to access to books and other reading materials as an important factor in attempting to explain why the summer months produce differential growth in reading.

Research has shown that there is a strong relationship between SES and access to books and other reading materials. In Bradley, Corwyn, McAdoo, and Coll's (2001) analysis of data from the National Longitudinal Survey of Youth (NLSY), children from poor families (those meeting the federal definition of poverty) were far less likely than non-poor children to have 10 or more books. The SES difference in the proportion of children owning 10 or more books was $.57 \mathrm{SD}$ in early childhood (3-5 years) and .25 SD in middle childhood (6-12 years). Neuman and Celano (2001) compared access to print in two low-income and two middle-income communities by directly observing the quantity and selection of children's books and magazines that were available in stores, child care centers, and local elementary school and public libraries, as well as environmental print (e.g., signs). There were striking SES differences in all of these forms of access. For example, over 16,000 children's titles were readily available for purchase in the highest SES neighborhood, compared to 55 in the lowest. A similar study by Constantino (2005) comparing high-SES and low-SES neighborhoods also found large differences in the number of books in homes, classrooms, and school and public libraries.

Family support for reading and literacy can be operationally defined in many different ways. One of the most straightforward and widely used measures, the frequency with which a parent reads to the child, is strongly associated with SES. Bradley et al. (2001) found that nonpoor mothers were more likely than poor mothers to read to their children three or more times per week, with this difference being most pronounced in early childhood. Burkam et al. (2004) found that, compared to the middle-SES groups, low-SES parents were significantly less likely to read a book to their child in the summer between kindergarten and first grade, while high-SES parents were more likely to read a book to their child. A similar pattern was evident for taking the child to a library or bookstore. 
An ethnographic study of fourth grade children's summer activities by Chin and Phillips (2004) provides insight into the ways in which family support for literacy differs as a function of SES and how SES differences could contribute to summer learning differences. Chin and Phillips (2004) found that the parents of working-class children often went out of their way to obtain books and educational materials for their children to use in the summer. But they were less skilled at organizing and facilitating literacy-related activities and making them appealing for their children, and less knowledgeable about their children's capabilities. For example, a middle-class mother organized a book club for her daughter, five other girls, and their mothers. A working-class mother purchased \$45 worth of Harry Potter books for her daughter but did not realize that the books were too difficult for her to comprehend.

Access and amount of summer reading. Heyns (1978) found that the number of books sixth and seventh grade students read during the summer was related to both frequency of use of a public library and the distance from the student's home to the library. Kim (2004) surveyed students in the summer following fifth grade and found a significant relationship between access to books and number of books read. Access was measured on a 12-point scale that was based on students' responses (ranging from "strongly agree" to "strongly disagree”) to three statements: "It's easy for me to find books to read at home during summer vacation," "It's easy for me to find books to read at the public library during summer vacation," and "It's easy for me to buy books to read during summer vacation.” The number of books read was assessed by asking students to list as many as five titles of books they read and verifying each title in an electronic catalogue of books for children and young adults. Only verified titles counted as a book read. Studies by Morrow (1992) and McQuillan and Au (2001) also indicate a relationship between access to books and amount of reading, although these studies focused on reading during the school year. In Morrow's (1992) study second graders in classrooms that added literacy centers reported large increases in the number of books and magazines they read. McQuillan and Au (2001) found that seventh grade students who were taken to the library by their teachers reported more free reading.

Summer reading and fall reading achievement. The crucial link is between summer reading and fall reading achievement, and it is well supported by research. In Heyns (1978) landmark study, hours spent reading and books read were significantly related to fall reading achievement with spring reading achievement, family income, parental education, and household size controlled. Thus the effect of reading was independent of SES, suggesting that "increasing access to books and encouraging reading may well have substantial impact on achievement” (Heyns, 1978, p. 172). Entwisle et al. (1997) also found that the number of books read by children in the summer predicted summer learning independent of SES.

Several studies have replicated Heyn’s (1978) findings in recent years. Like Heyns (1978), all of these investigators controlled for spring scores and socioeconomic status, and they included a variety of additional covariates as controls (e.g., demographic characteristics, parent's expectations, teacher ratings, students' attitude toward reading). Phillips and Chin (2004) found that children who read more than 30 minutes per day in the summer had higher reading comprehension scores in the fall. Burkam et al. (2004) found a significant relationship between fall reading and a composite of seven literacy-related summer activities that included frequency 
of the child reading a book on his or her own and number of visits to a library or bookstore. Finally, Kim (2004) found a significant relationship between books read in the summer and fall reading comprehension scores. The Kim (2004) study incorporated two significant improvements in methodology: Rising sixth grade students were asked directly about their reading activities during the summer, and the book reading measure was validated against a list of actual titles. The other studies including Heyns (1978) relied on parents' retrospective reports of their children's summer reading that were collected after school began in the fall.

Other variables. Other variables that could influence fall reading achievement include summer school attendance and summer activities not involving reading, such as taking a trip or visiting a museum. Some studies have found that attending summer school does not affect fall achievement while reading does (Burkam et al., 2004; Phillips \& Chin, 2004). With regard to summer activities other than reading, both Heyns (1978) and Entwisle et al. (1997) found that taking a trip was related to summer gains. However, Heyns' results suggested that "the single summer activity that is most strongly and consistently related to summer learning is reading” (p. 161). This conclusion is supported by the findings of Burkam et al. (2004), who found no effect for summer trips, and Phillips and Chin (2004), who found only a weak effect of going to museums on summer learning ( $p<.10$, weaker than reading).

\section{Can Summer Silent Reading Programs Reduce the SES Reading Achievement Gap?}

The above explanation of why low-SES children make less progress in reading during the summer and the supporting evidence reviewed were for us a good start towards developing a summer intervention. It suggested that to improve the reading achievement of low-SES children, we needed to increase both their access to books and the volume of reading they do in the summer. In addition, it indicated that it may be helpful to guide or structure the children's reading activities in some way, much as the middle-class parents did in Chin and Phillips' (2004) ethnographic study. This, however, was only the first step in developing an effective program of silent summer reading.

\section{Development of the Summer Reading Program}

Development of our summer reading program began with a question: Were there any experimental studies of well-designed voluntary reading interventions that were successful in encouraging more reading and improving reading achievement among elementary school-age children? The National Reading Panel (NRP; National Institute of Child Health and Human Development, 2000) had reviewed 14 experimental and quasi-experimental studies of sustained silent reading (SSR) and similar instructional approaches that typically involve asking students to select their own reading material, little monitoring, and no discussion or written follow-up assignment. The NRP's controversial conclusion was that there was little evidence that "encouraging reading has a beneficial effect on reading achievement” (p. 3-28). However, the panel members suggested that the dearth of experimental evidence "does not mean that procedures that encourage students to read more could not be made to work-future studies should explore this possibility" (p. 3-28). Thus, the NRP left open the possibility that voluntary reading could be made more effective and encouraged researchers to pursue the question of how. 
Book matching. One of the studies reviewed by the NRP was thought-provoking. Carver and Liebert (1995) found that elementary children who spent 15-30 hours reading library books in a school-based summer reading program did not gain in reading level, vocabulary, or reading rate. They interpreted this result as being due to the fact that the children read books that were too easy for them. Although most children were reading at the fifth grade level, they chose to read books at the third and fourth grade level. Other researchers had stressed the importance of text difficulty in silent or free reading (e.g., Byrnes, 2000; Stahl, 2004), and we knew that controlling the difficulty of text improves both oral reading fluency and reading comprehension (e.g., Shany \& Biemiller, 1995). We concluded that the quality of the match between children's skill levels and the texts they are reading was a potentially important ingredient in an effective silent summer reading program. At the time, we were unaware of the work of Reutzel, Jones, Fawson, \& Smith (2008) who were developing an instructional technique for teachers to use during the school year called "scaffolded silent reading" (ScSR). One of the key features of ScSR is teacher assignment of texts that are at students' independent reading level.

We also believed that children should have an opportunity to read books that tap into their personal interests because this enhances their motivation to read independently (Guthrie \& Humenick, 2004). Thus we concurred with Morrow’s (2003) suggestion that providing highinterest books that match students' reading preferences as well as their reading levels is essential for encouraging voluntary reading outside school, and we adopted children's interests and preferences as a second potentially important element. We knew these principles had been applied previously in practical settings. For example, in a summer reading program described by Borduin and Cooper (1997), teachers assessed children's text reading levels and administered an interest survey to guide their selection of books.

Teacher and parent support. Kim (2004) found that children read more books over the summer when they fulfilled a teacher request to write about a book they had read. This suggested that teachers might encourage summer reading - an important but hardly novel idea. Chin and Phillips (2004) made a similar suggestion, based on their finding of a modest relationship $(\mathrm{p}<.10)$ between summer gains in reading comprehension and the frequency with which teachers had assigned reading-related projects in the spring (e.g., writing a report or making an oral presentation). Also, there were scattered reports in the literature of summer reading programs that incorporated teacher support. For instance, Baron (1999) described a Connecticut school where teachers aimed to reduce the summer dip by mailing books to children and asking them to respond to the books on a postcard to be mailed to the teacher.

Kim (2004) also found that children read more books in the summer when their parents signed a form verifying that they had read at least one book from among a list of recommended titles. This indicated that parents as well as teachers might be enlisted to support summer reading, at minimum by monitoring it to provide a kind of accountability. At about the same time, Stahl (2004) pointed to monitoring as an important and often neglected component of SSR in classrooms.

Book matching and teacher and parent support. Kim (2007) studied the effects of a voluntary summer reading intervention for first through fifth grade children that incorporated book matching and teacher and parent support. In the late spring, the children took the reading portion of the Stanford Achievement Test as a pretest and also completed a 20-item survey of 
their reading preferences. Then they were randomly assigned to a treatment condition in which they received 10 books during the summer vacation (i.e., last week of June to first week of September) or a control condition in which they received 10 books after re-administration of the Stanford reading test as a posttest in the fall. A fall reading survey administered after the posttest included questions about book ownership and summer reading activity.

The following procedures were used to accomplish book matching and provide teacher and parent support in Kim's (2007) experiment. A two-step computer algorithm identified books that matched (a) each child's reading preferences based on the reading survey and (b) each child's independent reading level based on a range of 50 Lexiles above to 100 Lexiles below the child's observed Lexile score from the Stanford test given in the spring. Teachers supported the children's summer reading by conducting a "lesson" near the end of the school year. In the lesson, the teacher explained that the children were part of a program in which they would receive 10 books during the summer or in the fall. Along with each book, they would receive a postcard with several questions that they should answer before returning it: (a) "Did you finish reading your new book?” (b) “Did you like reading this book?” (c) "Was this book easy to read?" In addition, their parents would receive a letter requesting that they remind them to read the book.

In Kim's (2007) experiment, children in the treatment group reported reading significantly more books in the summer than children in the control group, about 3 more books on average. Also, only 3\% of the low-income children in the treatment group reported owning 0-10 books (the lowest category on the survey), whereas 32\% of the children in the control group did so. Further, the books were well matched to the children's interests and reading levels, and teachers and parents encouraged and supported the children's reading, although the level of support might be described as "minimal." However, despite book matching and some teacher and parent support, and despite the observed impact of the treatment on summer reading and book ownership, there was no difference in reading achievement between the treatment group and the control group. It was clear that something more was needed.

Book matching and teacher and parent scaffolding. Kim (2007) suggested that to strengthen the efficacy of summer reading programs, teachers could "scaffold" silent reading activities by instructing children how to use strategies to monitor their comprehension of text (Meichenbaum \& Biemiller, 1998; Pressley, 2002; Rosenshine \& Meister, 1994). For example, during lessons conducted at the end of the school year, teachers could instruct children to use multiple strategies to improve their reading comprehension in the summer. If children were reminded to apply comprehension strategies in silent reading and they did so, this might also increase the degree to which they are actively engaged in reading and motivated to understand what they are reading, particularly if they know they will be explaining what they read to a parent.

Although the NRP (2000) found no convincing evidence of positive effects for voluntary reading, it did find that the use of multiple comprehension strategies produced significant gains on reading assessments. The NRP also found that guided oral reading of text improved reading comprehension. Our awareness of this second evidence-based instructional strategy led to the final development in our thinking about an effective summer reading program: Teachers could 
scaffold fluent oral reading in end-of-the-year lessons, and parents could scaffold summer reading by providing an opportunity for their children to practice oral reading of a text they had previously read silently. Thus, prior research suggested that children might benefit from summer reading if they were explicitly taught to use comprehension strategies during silent reading of text and instructed to practice oral reading with a family member.

Logic model for our studies of scaffolded silent summer reading. Putting the pieces together, Figure 2 displays the logic model that underlies our studies of scaffolded silent summer reading. In essence, fall reading achievement is influenced by the amount of scaffolded silent summer reading of matched and interesting books that children do.

Figure 2-Logic Model for Studies of Scaffolded Silent Summer Reading

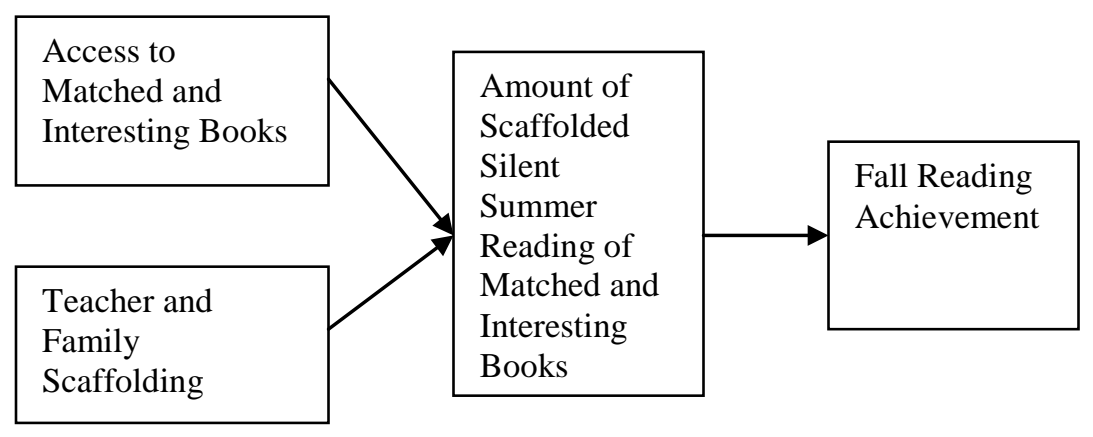

To provide scaffolding for children's summer reading, we ask teachers to implement several lessons at the end of the school year. In these lessons the teacher teaches students to use comprehension strategies that they can apply at home during the summer when they are reading silently and independently. The teacher also provides oral reading fluency practice, encourages students to read aloud to their parents over the summer, and shows them a simple procedure for doing so. We also ask parents to listen as their sons or daughters tell them about a book they had read during the summer, listen as a short passage from the book is read out loud by the child, and provide feedback on the degree to which the child reads smoothly and with expression.

We regarded the end-of-year lessons by teachers as a form of scaffolding because they involved modeling and explicit teaching of comprehension strategies and fluency, guided practice, and independent application (see, e.g., Clark \& Graves, 2005; Kuhn et al., 2006). Scaffolding may also include efforts to support students' motivation to read, as the parents in our studies did, by listening to the oral reading and explanation of a book (e.g., Lutz, Guthrie, \& Davis, 2006). In parallel fashion, Reutzel et al. (2008) developed a Scaffolded Silent Reading (ScSR) procedure for classroom use that attempts to foster children's motivation to read, reading comprehension, and fluency by having children not only read silently on their own but also read aloud to the teacher and complete book response projects.

\section{The Experiments and the Program ${ }^{9}$}

\footnotetext{
${ }^{9}$ The text that follows has been adapted from White and Kim (2008). We thank the International Reading Association for granting permission to re-use this material.
} 
In the first of our two experiments (Kim, 2006), fourth-grade children received lessons from their teacher at the end of the school year. In these lessons, the teacher modeled fluent oral reading and comprehension strategies for silent reading. The children practiced fluent oral reading in a paired reading format and practiced using five reading comprehension strategies while reading silently on their own. In the summer, the treatment group received matched books and parent scaffolding that consisted of listening as the student talked about a book, listening as a 100 -word passage from the book was read aloud and then reread, providing general feedback, and signing a postcard to be mailed to the researchers with an optional comment about the summer reading experience. The control group received no books and no parent scaffolding in the summer, but did receive books in the fall after posttesting to satisfy ethical requirements.

Positive effects on reading achievement were observed in the Kim (2006) experiment, but considering the controversy over the benefits of silent reading, we believed that replication with a different sample of schools and additional grade levels was important. In addition, it is possible that the same results would have been obtained if children simply received the matched books without any support from their teachers or parents, or if children received only oral reading practice without comprehension strategies instruction. Therefore, we conducted a second experiment (Kim \& White, 2008) with four groups of children in grades 3 through 5:

1. matched books only (Books Only)

2. matched books and oral reading (Books With Oral Reading Scaffolding)

3. matched books, oral reading, and comprehension strategies instruction (Books With Oral Reading and Comprehension Scaffolding)

4. control group receiving books in the fall after posttesting and no teacher or parent scaffolding (Control)

Participants. Both experiments were conducted in a large suburban school district in the Mid-Atlantic region of the United States. In the first experiment the participants were 34 teachers and 486 children who were completing grade 4 in one of 10 elementary schools. Nonwhite ethnic minorities (Black, Hispanic, Asian, and other) were predominant (67\%), and 39\% of the children were receiving free- or reduced-price lunch. In the second experiment, the participants were 24 teachers and 400 children who were completing grade 3 , grade 4 , or grade 5 in one of two elementary schools. The children's characteristics were similar: $69 \%$ non-white and 38\% receiving free- or reduced-price meals. Children with special education needs who could not be tested under standard conditions were excluded from the experiments. About $8 \%$ of the tested children tested were classified as learning disabled.

Prior research informed our decision to target the intervention to children in the third through fifth grade. Most voluntary reading interventions have focused on students who are old enough to have mastered basic decoding skills and are capable of improving their reading through reading (Byrnes, 2000; Share, 1999). For example, 12 of the 14 studies on voluntary reading reviewed by the NRP involved students in grade 3 or higher. Although Kim (2007) found no significant effects for summer reading, treatment-control differences were larger in the third and fifth grades than in the first and second grades.

Treatment and control groups. In the first experiment, all children including those in the control group received the three end-of-year lessons. (We assumed-and this assumption was later borne out by the data-that there would be minimal lesson effects for the control group 
because the children got no books in the summer and thus no opportunity to practice what they were taught in the lessons.) Within each of the participating teachers' classes, children were randomly assigned to either the treatment group or the control group. The treatment group received matched books and parent scaffolding of oral reading in the summer. The control group received books in the fall after the posttests were administered and no parent scaffolding. In the second experiment, both teachers and children were randomly assigned to one of the four groups-Books Only, Books With Oral Reading Scaffolding, Books With Oral Reading and Comprehension Scaffolding, and Control. The Control group received no end-of-year lessons from their teacher, no books in the summer, and no parent scaffolding.

Measures. To determine the reading preferences we used to match books with students, teachers administered a survey that asked students how much they enjoyed reading books from one of 25 categories. The categories were initially developed from the Adventuring with Books list for pre-K to grade 6 students published by the National Council of Teachers of English (McClure \& Kristo, 2002), validated using other published surveys of students' reading preferences (Galda, Ash, \& Cullinan, 2000; Ivey \& Broaddus, 2001; Monson \& Sebesta, 1991; Summers \& Lukasevich, 1983), and reviewed and refined by four elementary teachers. To find out whether the intervention increased reading activity at home or access to books at home during the summer, teachers administered a survey in September. The survey included items that asked students to rate how often they had engaged in each of five reading activities and how many books there were in their homes.

To measure growth in the students' reading achievement over the summer, teachers administered the appropriate level of the Vocabulary and Reading Comprehension tests from the Iowa Tests of Basic Skills in the second week of June and the second week of September. Different forms of the test were used in June and September. The Vocabulary and Reading Comprehension test scores were combined to get a Total Reading score that was used in analyzing gains from pretest to posttest. The ITBS is highly reliable (KR-20 coefficients above 0.93 and equivalent form estimates of 0.86 or higher), and the levels are vertically equated to yield a continuous measure of reading achievement.

To measure growth in the students' oral reading fluency over the summer, trained retired teachers gave the Dynamic Indicators of Basic Early Literacy Oral Reading Fluency subtest (DIBELS ORF) during the week after the ITBS in June and again in September, using the same grade-appropriate passage (the mid-level passage recommended for students at the end of the grade they had just completed). The DIBELS ORF subtest reliably measures fluency in terms of words read correctly per minute. Good and Kaminski (2003) report alternate form reliability, and we found test-retest reliability of 0.89 in our data. DIBELS ORF also has good concurrent and predictive validity, showing correlations with reading comprehension that range from 0.54 to 0.80 (see Riedel, 2007).

The program. The program was implemented in four stages: teacher training, end-of-year lessons, book matching, and parent/family member support for summer reading. In early June, teachers attended a 2-hour training session conducted by an experienced elementary language arts teacher. This teacher trainer had developed the lessons to meet our specifications and fieldtested them in a grade 4 class prior to training. During training, she modeled a series of three 
lessons (described below) using an engaging, well-illustrated children's storybook, The Wreck of the Zephyr (Van Allsburg, 1983).

The end-of-year lessons were carried out over the course of several days by the participating classroom teachers following training. Each lesson was fully scripted and required no more than 45 minutes of class time. Lesson 1 focused on comprehension strategies. The teacher began by explaining to the children that they would be receiving books and postcards over the summer, and they would need to know what to do when they received them. She asked for the children's help in generating a list of five strategies that good readers use to help them understand what they are reading: reread, predict, ask questions, make connections, and summarize. These were strategies the teachers had already introduced and taught, so it was not difficult to elicit them. The teacher then read The Wreck of the Zephyr aloud, stopping at appropriate points to model one of the strategies. As each strategy was modeled, the children were asked to identify it, and the teacher rephrased their responses so they exactly matched the phrases they would see on the postcard. Next, the teacher demonstrated on an overhead transparency how to complete the questions on a postcard like the one the children would be receiving with their books (see Figure 3). Then, in the last part of the lesson, children selected a book, attached sticky notes where they used a comprehension strategy, shared their examples of strategy use with the class, and practiced answering the questions on the postcard. The fourth question asked them to place a check mark by each comprehension strategy they used.

\section{Figure 3-Postcard for Children Receiving Books with Oral Reading and Comprehension Scaffolding}

(Seek permission to reproduce Figure 1 from White \& Kim, 2008)

In Lesson 2, the focus was fluency practice. Following a review of comprehension strategies, the teacher stated, "Another thing that good readers do is read smoothly and with good expression when they are reading aloud." She asked the children how they knew if someone was a good reader when they read aloud, accepted their answers and said, "Yes, when someone reads aloud with good expression and at just the right speed without mistakes, we call that fluent reading." She wrote fluent reading on the board and beneath it, smooth, good expression, and correct. Then she explained that she would read a 100-word passage from The Wreck of the Zephyr several times, and the children would rate her reading. The first reading was poor, with lots of pauses and miscues; the second reading was better, with shorter pauses and no miscues but flat and expressionless; and the third reading was her best reading - smooth, full of expression, and errorless. Next, the teacher used an overhead transparency of the postcard to demonstrate how the children would be answering an additional question that was not discussed the day before: a three-part question that asked whether they read more smoothly, whether they knew more words, and whether they read with more expression. Finally, the teacher pointed out that postcard asked for a family member's signature and optional comment.

Lesson 2 continued with children pairing up, counting 100 words from a passage in a book, and practicing reading with their partners. One child read the passage aloud while the other gave feedback using the postcard rating categories, then the roles were reversed for a second reading. After paired reading, the children "mailed" their postcards by returning them to the teacher. 
They were given a homework assignment to independently read a book for 15 minutes, read aloud a 100-word passage to a family member twice, complete the questions on the postcard, and obtain a family member's signature.

Lesson 3 provided additional teacher modeling and practice with a nonfiction book. The teacher elicited and modeled comprehension strategies as before, modeled completion of the postcard questions, and modeled counting out 100 words and reading aloud with improvement shown. The children then practiced on their own (for silent reading and comprehension strategies) and with a partner (for oral reading and fluency practice).

In the first experiment, children received all three end-of-year lessons exactly as described above. In the second experiment, only the children in the Books With Oral Reading and Comprehension Scaffolding group received all three lessons. Children in the Books With Oral Reading Scaffolding group received two lessons that did not include comprehension strategies; and children in the Books Only group received a single lesson that included neither oral reading nor comprehension strategies instruction. For children in the Control group, the teacher prepared an alternative reading activity to use in place of the lessons.

Book matching. In both experiments, matched books were selected for each child by a computer algorithm that merged data from two files. One file contained a text difficulty (Lexile) level and preference categories for each of 240 available book titles. The second file contained each student's Lexile range from the June ITBS and reading preference ratings for the categories on the June survey. The algorithm generated a list of the eight books that represented the best matches for each child, those with high preference ratings within the child's Lexile range. For children in the treatment groups, one matched book was mailed each week for eight successive weeks from early July until the end of August. Children in the control group received all eight of their matched books at once in September after the posttests.

Parent/family member scaffolding of summer reading. Along with each book that was sent out, there was a postcard for the child and letter for the parent or other family member (translated into Spanish, Urdu, Arabic, or Vietnamese for parents who spoke one of these languages). The letter asked the parent to encourage their children to read and requested return of the postcard. Except for students in the Books Only group of the second experiment, the parent letter suggested that "It will help your child if he or she reads out loud to you, or to an older brother or sister," and requested that, "After you listen to your child reading out loud a second time, tell him or her how they improved." The postcard for the treatment group in the first experiment and the Books With Oral Reading and Comprehension Scaffolding group in the second experiment had all of the questions shown in Figure 3. The postcard was modified as needed to implement the Books Only and Books With Oral Reading Scaffolding treatment conditions in the second experiment (e.g., the postcard had no questions asking the student about his or her use of comprehension strategies).

\section{Findings}

First experiment. Table 1 displays the posttest mean Total Reading scores on the ITBS for all children in the treatment and control groups. The posttest scores were adjusted for pretest scores by means of an ANCOVA. Overall reading achievement was higher for the treatment 
group $(M=207.9)$ than the control group $(M=205.9)$. The difference of 2.0 points was just 0.01 short of the conventional 0.05 level of statistical significance at $p<0.06$, but it represented 1.3 additional months of school learning, so it is clearly significant in practical terms. We calculated additional months of school learning by dividing the difference between the treatment and control group means by 1.56, because children gain 14 points from the spring of grade 4 to the spring of grade 5 according to the test publisher's norm sample, or 1.56 points per month during a 9-month school year. Research (e.g., Cooper et al., 1996) suggests that achievement scores do not increase during the summer, so we divided 14 by 9 , not 12 .

\section{Table 1-Results of the First Experiment}

(Seek permission to reproduce Table 1 from White \& Kim 2008)

Table 1 also displays the ITBS results for low-income children and each ethnic group regardless of income. Black and Hispanic children derived the greatest benefit from the summer reading program, showing treatment effects that were about twice as large as the overall effect. For Black students, the difference between treatment and control conditions (5.2 points) represents 3.3 additional months of learning. For Hispanic students, the treatment-control difference is the equivalent of 2.1 additional months of learning. For Asian students, the control group performed better than the treatment group. This anomalous result may be related to the fact that the control group included a much higher proportion of females. It is possible that these Asian females were avid readers before the experiment began.

On the DIBELS ORF subtest, there was no overall difference between the treatment and control groups. One explanation for this finding is that the oral reading part of the treatment did not involve very much practice, just reading a 100-word passage from each book twice with the parent. So it is perhaps not surprising that the number of words read per minute did not increase. However, this does not mean that oral reading scaffolding was not beneficial. Oral reading may have improved comprehension through its emphasis on good expression, particularly falling and rising pitch (Miller \& Schwanenflugel, 2006). Or the opportunity to read to the parent may have motivated the children to read on their own.

Other data collected in the first experiment indicated that many of the children did read their books with a parent or family member. Slightly over half of the treatment group in each of the ethnic groups returned a postcard indicating that they read at least one book, and all but a few of the returned postcards had been signed by a parent or family member. Also, on two survey items measuring oral reading with a family member, the treatment group had significantly higher scores than the control group.

Second experiment. As in the first experiment, there was evidence that the intervention had an impact on the children's summer reading activity. On a scale that combined results from five items, there was a significant difference favoring the Books With Oral Reading and Comprehension Scaffolding group over the Control group. About half of the children in each treatment group returned at least one postcard indicating they had read at least one book, and about $25 \%$ returned four or more postcards indicating they had read at least four of the eight books. 
Figure 4 displays the overall ITBS results for each of the four experimental groups in terms of posttest means for Total Reading. (As before, these are adjusted means from an ANCOVA using the pretest as a covariate.) As expected, children in the Books Only group $(\mathrm{M}=203.6)$ performed similarly to children in the Control group $(M=203.1)$. Thus, as in the Kim (2007) experiment, simply providing matched books did not have a significant positive effect on reading achievement. The lack of positive effects for books only did not seem to result from the children having not read the books. The percentage of children who reported reading part or all of at least one book was actually higher for the Books Only group (55\%) than for the Books With Oral Reading and Comprehension Scaffolding group (49\%), as was the percentage of children who reported reading four or more of the eight books, 34\% and 23\%, respectively.

\section{Figure 4-Results of the Second Experiment}

(Seek permission to reproduce Figure 2 from White and Kim 2008)

Children in the full treatment group, Books With Oral Reading and Comprehension Scaffolding $(\mathrm{M}=207.0)$ significantly outperformed students in the Control group on the ITBS $(M=203.1 ; p<0.03)$. The difference in posttest scores of 3.9 points represents a learning advantage of 2.5 months.

Children in the Books With Oral Reading Scaffolding group $(\mathrm{M}=204.8)$ performed better than children in the Control group $(M=203.1)$ on the ITBS, and this difference was larger for children who were below the median on the fluency pretest $(M=204.8 \mathrm{vs.} \mathrm{200.7),} \mathrm{but} \mathrm{none} \mathrm{of}$ these differences were statistically significant. Thus the second experiment did not provide clear evidence on the question of whether oral reading scaffolding alone produces better reading outcomes.

For fluency as measured by the DIBELS ORF subtest, mean adjusted posttest fluency scores, in words read correctly per minute, were about the same for the Control group and two treatment groups, consistent with the first experiment. This finding of no treatment effect on fluency held for both the full sample and students who were below the median in fluency on the pretest.

Table 2 presents the main ITBS results for low-income, Black, White, and Hispanic children, comparing the Control group with the full treatment group, Books With Oral Reading and Comprehension Scaffolding. These data are directly comparable to the data in Table 1. Because there were fewer than 10 Asian children in each group, results for Asian students are not reported separately. The largest positive effects, ranging from 1.7 to 5.1 additional months of learning, were observed for Black, Hispanic, and low-income children. Low-income children gained an average of 4.0 months. Notably, this is enough to offset $100 \%$ of the summer loss shown by low-income students in Cooper et al.'s (1996) meta-analysis of studies of the effect of summer vacation on achievement, 0.34 grade-level equivalents or about 3 months.

Table 2-Results of the Second Experiment 
(Seek permission to reproduce Table 2 from White \& Kim 2008)

\section{Related Research and Similar Programs Implemented by Others}

In our studies, the intervention lasted for a single summer only, and we found that it was sufficiently effective to offset the amount of summer loss that is typically seen in low-income students. In subsequent summers, however, the low-income students who benefitted from the program are likely to have slipped behind their high-income peers. Thus to make a significant dent in the SES achievement gap, it may be necessary to implement a multi-year program of silent summer reading. In the only study of the impact of increasing access to books over consecutive summers on children's reading achievement that we are aware of, Allington and McGill-Franzen (2008) randomly assigned primary school children to a treatment group of 842 children or a control group of 428 children in 17 high-poverty elementary schools. Treatment group children received 12 self-selected paperback books for three consecutive summers. Children were encouraged to keep a book log each summer. After the third summer, the treatment group scored .14 standard deviations higher than the control group on the Florida Comprehensive Assessment Test (FCAT), and the effect size was somewhat larger for the poorest students $(\mathrm{ES}=.21)$.

Since the conclusion of our two experiments, a number of school districts have implemented similar programs of silent summer reading. For example, in Durham, North Carolina during the summer of 2008, Communities in Schools, a dropout prevention organization, and Metametrics, Inc., a Durham-based testing firm, partnered with local school administrators and teachers to implement a silent summer reading program. The program was based on our earlier experimental studies and was designed to increase children's access to matched books during the summer. The study involved 88 third and fourth grade children from two schools who were below reading level as measured by the North Carolina End-of-Grade assessments in reading. These children were administered a pre and posttest comprehension measure developed by Metametrics (Vitiello, 2008). Children's Lexile levels ranged from 120L to 990L (Lexiles), which corresponded to the mean reading level of children in first- to sixthgrade.

Book fairs were held to select matched and interesting books for the children to read during the summer. Since the book fairs were held after the school year ended, dinner was provided for parents and their children to increase participation. Approximately 230 books that accommodated the wide range of reading level were purchased from Barnes \& Noble and Scholastic. The books were organized into 1 of 6 Lexile levels ranging from (1) below 300L, (2) 300-400L, (3) 401-500L, (4) 501-600L, (5) 601-700L, and (6) 700 Lexiles and above. Books were color coded to correspond to the appropriate Lexile zone. Staff and volunteers used Lexile scores from the pretest reading measure to direct children to one of the six Lexile zones, and children were allowed to choose eight books that interested them and fell within their zone. The children were informed that they would receive the chosen books in the mail in July and August, and they were also encouraged to return a postcard after reading each book.

Staff from Metametrics examined whether pretest to posttest reading Lexile gains were related to the number of books children reported reading as measured by their postcard return 
rate. The results revealed a moderate relationship between reading growth in Lexiles and the number of books children reported reading during the summer. Children who read more than half of their books ( 5 to 8 books) enjoyed an average gain of more than 80 Lexiles, whereas children who read fewer than half of their books (0 to 4 books) lost ground during the summer. For example, children who read only 0 to 1 book underwent a decline of approximately 50 Lexiles, on average. Because there was no comparison group and children were not randomly assigned to receive different numbers of books, no firm causal conclusions can be drawn.

Despite the limitations of correlational evidence, the Durham program provides an example of adapting a silent reading program to fit within the resource constraints of a local school district. Importantly, the Durham program did match books to readers, but the strategy for doing so - a leveled book fair - was different from the strategy we had employed in our two experiment experiments. Equally important, there was also an effort to evaluate the efficacy of the program.

\section{Recommendations for Researchers and Policymakers}

In future years, we suspect that policymakers and practitioners will become more interested in adopting scaffolded silent summer reading programs. Given the budget deficits at all levels of government, school districts are unlikely to have the resources to implement costly summer school programs. At the same time, federal and state accountability mandates will continue to hold schools responsible for reducing achievement gaps, especially those based on children's socioeconomic status. Both budget constraints and accountability demands are likely to fuel the debate about the most cost-effective approaches to reduce achievement gaps and implement silent summer reading programs. We conclude this chapter by offering several recommendations for researchers and policymakers pursuing these goals.

First, researchers and policymakers should continue to examine the question of whether increasing the quantity and quality of silent summer reading activities improves reading achievement for low-income children. As noted in the first part of this chapter, sociological research suggests that children must have access to books at home to enjoy gains in reading comprehension during the summer months. The Allington and McGill-Franzen (2008) study is exemplary in its use of a longitudinal design to test the impact of increasing access to books across multiple summers. Findings from this experimental study suggest that a longer intervention spanning multiple summers may enhance the efficacy of silent reading programs. In future work, researchers should continue to pursue the question of whether a multi-year silent summer reading program can generate long-term, cumulative, and practically significant effects on reading achievement.

Our research has suggested that qualitative differences in children's silent reading activities also matter. The quality of children's silent reading experiences, as measured by the match between readers and texts, may be as important as quantitative differences in children's access to books and opportunities to read. We are certainly not alone in pointing to the match between text and reader (see, for example, Hiebert \& Sailors, 2008). In the Allington and McGillFranzen study, children were allowed to self-select books without regard to their difficulty. From our perspective, their positive results are somewhat surprising. But the point we wish to 
emphasize is that to date there has been no study of a silent summer reading program that increased access to matched books for multiple summers.

Second, researchers and policymakers should articulate a clear logic model for their silent summer reading program. Our logic model (Rossi, Lipsey, \& Henry, 2004) describes the critical program components through which a silent summer reading program may improve reading achievement. Based on our review of research, we proposed that increasing children's access to matched books and teacher and family scaffolding are needed to increase silent reading activities in the summer and to improve reading achievement. An important goal of our two experimental studies was to test the logic model outlined in Figure 2. Results from our two studies indicated that both program components - access to matched books and teacher and family scaffoldingwere needed to improve children's reading comprehension.

A logic model can also predict the conditions under which an intervention may not improve student outcomes. Kim and Guryan (In press) allowed 400 low-income Latino children who had just completed fourth grade to self-select 10 books for summer reading at an end-of-year book fair. Most children did not choose 10 books that were matched to their reading level. Specifically, $67 \%$ of the children selected 10 books with a mean readability level above their independent reading level. In addition, many parents and children did not attend the family literacy events that were offered in an attempt to increase parent support or scaffolding for summer reading. Consistent with the logic model in Figure 2, children who received ten books and whose parents were invited to the family literacy events scored no higher on the GatesMacGinitie Reading Test administered in the fall than children who received no books in the summer.

Third, policymakers should insist upon evaluation of any silent summer reading programs that are implemented to determine if they are effective, particularly in reducing socioeconomic disparities in reading achievement. Evaluation is critical because there is no guarantee that positive results from a silent reading intervention in one district will be easily replicated in a district with different groups of children. Local adaptations of silent reading programs will inevitably lead to variations in program design, and these variations (e.g., the strategy for matching books to readers, the duration of the intervention, and the English proficiency of the children in the program) are likely to affect the results. The Durham program is noteworthy because there was not only an intervention to address the problem of summer reading loss but also a plan to collect data on children's summer reading activity and progress in reading comprehension. We encourage other school districts to intervene to address the problem of summer loss and to simultaneously evaluate their efforts by measuring both children's reading skills and the amount of summer reading. 


\section{References}

Aikens, N.L., \& Barbarin, O. (2008). Socioeconomic differences in reading trajectories: The contribution of family, neighborhood, and school contexts. Journal of Educational Psychology, 100, 235-251.

Alexander, K.L., Entwisle, D.R., \& Olson, L.S. (2001). Schools, achievement, and inequality: A seasonal perspective. Educational Evaluation and Policy Analysis, 23, 171-191.

Alexander, K.L., Entwisle, D.R., \& Olson, L.S. (2004). Schools, achievement, and inequality: A seasonal perspective. In G.D. Borman \& M. Boulay (Eds.), Summer learning: Research, policies, and programs. Mahwah, New Jersey: Lawrence Erlbaum Associates.

Allington. R. L., \& McGill-Franzen, A. M., (2008). Got books. Educational Leadership, 65, 2023.

Baron, J.B. (1999). Exploring high and improving reading achievement in Connecticut. Washington, DC: National Education Goals Panel.

Becker, W.C. (1977). Teaching reading and language to the disadvantaged-What we have learned from field research. Harvard Educational Review, 47, 518-543.

Benson, J.G., \& Borman, G.D. (2007). Family and contextual socioeconomic effects across seasons: When do they matter for the achievement growth of young children? (WCER Working Paper 2007-5). Madison, WI: University of Wisconsin, Center for Education Research.

Biemiller, A. (1999). Language and reading success. Newton, MA: Brookline Books.

Borduin, B.J., \& Cooper, E.D. (1997). Summer reading pals. The Reading Teacher, 50, 702.

Borman, G.D., \& Dowling, N.M. (2006). Longitudinal achievement effects of multiyear summer school: Evidence from the Teach Baltimore randomized field trial. Educational Evaluation and Policy Analysis, 28, 25-48.

Bradley, R.H., Corwyn, R.F., McAdoo, H.P., \& Coll, C.G. (2001). The home environments of children in the United States Part I: Variations by age, ethnicity, and poverty status. Child Development, 72, 1844-1867.

Burkam, D.T., Ready, D.D., Lee, V., \& LoGerfo, L.F. (2004). Social-class differences in summer learning between kindergarten and first grade: Model Specification and Estimation. Sociology of Education, 77, 1-31.

Byrnes, J.P. (2000). Using instructional time effectively. In L. Baker, M.J. Dreher, \& J.T. Guthrie (Eds.), Engaging young readers (pp. 188-208). New York: Guilford.

California Department of Education. (1999). Reading/language arts framework for California public schools, kindergarten through grade twelve. Sacramento, CA: Author.

Carver, R.P., \& Liebert, R.E. (1995). The effect of reading library books at different levels of difficulty upon gain in reading ability. Reading Research Quarterly, 30, 26-48.

Chall, J.S. (1983). Stages of reading development. New York: McGraw-Hill.

Chall, J.S., Jacobs, V.A., \& Baldwin, L.E. (1990). The reading crisis: Why poor children fall behind. Cambridge, MA: Harvard University Press.

Cheadle, J.E. (2008). Educational investment, family context, and children's math and reading growth from kindergarten through the third grade. Sociology of Education, 81, 131.

Chin, T., \& Phillips, M. (2004). Social reproduction and child-rearing practices: Social class, children's agency, and the summer activity gap. Sociology of Education, 77, 185-210.

Clark, K.F., \& Graves, M.F. (2005). Scaffolding students' comprehension of text. The Reading Teacher, 58, 570-580. 
Cooper, H., Nye, B., Charlton, K., Lindsay, J., \& Greathouse, S. (1996). The effects of summer vacation on achievement test scores: A narrative and meta-analytic review. Review of Educational Research, 66, 227-268.

Constantino, R. (2005). Print environments between high and low socioeconomic status communities. Teacher Librarian, 32, 22-25.

Downey, D.B., von Hippel, P.T., \& Broh, B.A. (2004). Are schools the great equalizer? Cognitive inequality during the summer months and the school year. American Sociological Review, 69, 613-635.

Entwisle, D.R., Alexander, K.L., \& Olson, L.S. (1997). Children, schools, and inequality. Boulder, CO: Westview Press/HarperCollins Publishers, Inc.

Galda, L., Ash, G.E., \& Cullinan, E. (2000). Children’s literature. In M.L. Kamil, P.B. Mosenthal, P.D. Pearson, \& R. Barr (Eds.), Handbook of reading research (Vol. 3, pp. 361380). Mahwah, NJ: Erlbaum.

Good, R.H., \& Kaminski, R.A. (2003). Dynamic Indicators of Basic Early Literacy Skills (6th ed.). Eugene, OR: Institute for the Development of Educational Achievement, University of Oregon.

Guthrie, J.T., \& Humenick, N.M. (2004). Motivating students to read: Evidence for classroom practices that increase reading motivation and achievement. In P. McCardle \& V. Chhabra (Eds.), The voice of evidence in reading research (pp. 329-354). Baltimore: Paul H. Brookes. Hart, B., \& Risley, T.R. (1995). Meaningful differences in the everyday experience of young American children. Baltimore: Brookes Publishing.

Heyns, B. (1978). Summer learning and the effects of schooling. New York: Academic.

Hiebert, E. H. \& Sailors, M. (Eds.). (2008). Finding the right texts. New York: Guilford Press.

Ivey, G., \& Broaddus, K. (2001). "Just plain reading”: A survey of what makes students want to read in middle school classrooms. Reading Research Quarterly, 36, 350-377.

Kim, J.S. (2004). Summer reading and the ethnic achievement gap. Journal of Education for Students Placed at Risk, 9, 169-188.

Kim, J.S. (2006). Effects of a voluntary summer reading intervention on reading achievement: Results from a randomized field trial. Educational Evaluation and Policy Analysis, 28, 335355.

Kim, J.S. (2007). The effects of a voluntary summer reading intervention on reading activities and reading achievement. Journal of Educational Psychology, 99, 505-515.

Kim, J.S., \& White, T.G. (2008). Scaffolding voluntary summer reading for children in grades 3 to 5: An experimental study. Scientific Studies of Reading, 12, 1-23.

Kim, J.S., \& Guryan, J. (In press). The Efficacy of a Voluntary Summer Book Reading Intervention for Low-Income Latino Children from Language Minority Families. Journal of Educational Psychology.

Kuhn, M.R., Schwanenflugel, P.J., Morris, R.D., Morrow, L.M., Woo, D.G., Meisinger, E.B., et al. (2006). Teaching children to become fluent and automatic readers. Journal of Literacy Research, 38, 357-387.

Lai, M.K., McNaughton, S., Amituanai-Toloa, M., Turner, R., \& Hsiao, S. (2009). Sustained acceleration of achievement in reading comprehension: The New Zealand experience. Reading Research Quarterly, 44, 30-56.

Lee, J., Grigg, W., and Donahue, P. (2007). The Nation's Report Card: Reading 2007 (NCES 2007-496). National Center for Education Statistics, Institute of Education Sciences, U.S. Department of Education, Washington, D.C. 
LoGerfo, L., Nichols, A., \& Reardon, S.F. (2006). Achievement gains in elementary and high school. Washington, DC: Urban Institute.

Lutz, S.L., Guthrie, J.T., \& Davis, M.H. (2006). Scaffolding for engagement in elementary school reading instruction. The Journal of Educational Research, 100, 3-20.

McCoach, D.B., O’Connell, A.A., Reis, S.M., \& Levitt, H.A. (2006). Growing readers: A hierarchical linear model of children's reading growth during the first 2 years of school. Journal of Educational Psychology, 98, 14-28.

McQuillan, J., \& Au, J. (2001). The effects of print access on reading frequency. Reading Psychology, 22, 225-248.

McClure, A.A., \& Kristo, J.V. (2002). Adventuring with books: A booklist for pre-K-grade 6. Urbana, IL: National Council of Teachers of English.

Meichenbaum, D., \& Biemiller, A. (1998). Nurturing independent learners. Cambridge, MA: Brookline.

Mesmer, H. A. E., \& Cumming, S. (2008). Text-reader matching: Meeting the needs of struggling readers. In E. H. Hiebert \& M. Sailors. Finding the right text (pp. 149-176). New York: The Guilford Press.

Miller, J., \& Schwanenflugel, P.J. (2006). Prosody of syntactically complex sentences in the oral reading of young children. Journal of Educational Psychology, 98, 839-853.

Monson, D.L., \& Sebesta, S. (1991). Reading preferences. In J. Flood (Ed.), Handbook of research on teaching the English language arts (pp. 664-673). New York: Macmillan.

Morrow, L.M. (1992). The impact of a literature-based program on literacy achievement, use of literature, and attitudes of children from minority backgrounds. Reading Research Quarterly, $27,250-275$.

Morrow, L.M. (2003). Motivating lifelong voluntary readers. In J. Flood, D. Lapp, J.R. Squire, \& J.M. Jensen (Eds.), Handbook of research on teaching the English language arts (2nd ed., pp. 857-867). New York: Macmillan.

Nagy, W. E., Anderson, R. C., \& Herman, P. A. (1987). Learning word meanings from context during normal reading. Reading Research Quarterly, 24, 237-270.

National Institute of Child Health and Human Development. (2000). Report of the National Reading Panel. Teaching children to read: An evidence-based assessment of the scientific research literature on reading and its implications for reading instruction (NIH Publication No. 00-4769). Washington, DC: U.S. Government Printing Office.

Neuman, S.B., \& Celano, D. (2001). Access to print in low-income and middle-income communities: An ecological study of four neighborhoods. Reading Research Quarterly, 36, 826.

Phillips, M., \& Chin, T. (2004). How families, children, and teachers contribute to summer learning and loss. In G. Borman \& M. Boulay (Eds.), Summer learning: Research, policies, and programs (pp. 255-278). Mahwah, NJ: Erlbaum

Phillips, M., Crouse, J. \& Ralph, J. (1998). Does the black-white test score gap widen after children enter school? In C. Jencks \& M. Phillips (Eds.), The black-white test score gap (pp. 229-272). Washington, DC: Brookings Institution.

Pressley, M. (2002). Reading instruction that works (2nd ed.). New York: Guilford Press.

Reutzel, D.R., Jones, C.D., Fawson, P.C., \& Smith, J.A. (2008). Scaffolded silent reading: Oral reading that works! The Reading Teacher, 62, 194-207.

Riedel, B.M. (2007). The relation between DIBELS, reading comprehension, and vocabulary in urban first-grade students. Reading Research Quarterly, 42, 546-567. 
Rosenshine, B., \& Meister, C. (1994). Reciprocal teaching: A review of the research. Review of Educational Research, 64, 181-221.

Rossi, P. H., Lipsey, M. W., \& Freeman, H. E. (2004). Evaluation: A systematic approach, $7^{\text {th }}$ ed. Thousand Oaks, CA: Sage Publications.

Shany, M.T., \& Biemiller, A. (1995). Assisted reading practice: Effects on performance for poor readers in Grades 3 and 4. Reading Research Quarterly, 30, 382-395.

Share, D.L. (1999). Phonological recoding and orthographic learning: A direct test of the selfteaching hypothesis. Journal of Experimental Child Psychology, 72, 95-129.

Stahl, S. A. (2004). What do we know about fluency? Findings of the National Reading Panel. In P.McCardle \& V. Chhabra (Eds.), The voice of evidence in reading research (pp. 187-212). Baltimore: Brookes.

Summers, E.G., \& Lukasevich, A. (1983). Reading preferences of intermediate-grade children in relation to sex, community, and maturation (grade level): A Canadian perspective. Reading Research Quarterly, 18, 347-360.

Swanborn, M. S. L., \& de Glopper, K. (1999). Incidental word learning while reading: A metaanalysis. Review of Educational Research, 69, 261-285.

Van Allsburg, C. (1983). The wreck of the Zephyr. Boston: Houghton Mifflin.

Vitiello, C. (2008). Durham READS: Summer reading results. Durham, NC: Metametrics, Inc. White, T.G., \& Kim, J.S. (2008). Teacher and parent scaffolding of voluntary summer reading. The Reading Teacher, 62, 116-125.

White, T.G., Graves, M.F., \& Slater, W.H. (1990). Growth of reading vocabulary in diverse elementary schools: decoding and word meaning. Journal of Educational Psychology, 82, 281290. 